\title{
Biochemical Parameter Derangement in Commercial Broilers during Heat Stress and Their Mitigation using Ascorbic Acid Supplementation
}

\author{
Amir Amin Sheikh ${ }^{1,2 *}$, Aditya Mishra ${ }^{1}$, Burhan Nabi ${ }^{3}$ and Omer Mohi U din Sofi ${ }^{4}$ \\ ${ }^{1}$ Department of Veterinary Physiology and Biochemistry, College of Veterinary Science and Animal Husbandry, NDVSU, \\ Jabalpur (M.P), INDIA \\ ${ }^{2}$ Division of Veterinary Physiology and Biochemistry, Faculty of Veterinary Sciences \& Animal Husbandry, \\ SKUAST-Jammu, INDIA \\ ${ }^{3}$ Division of Veterinary Medicine, Faculty of Veterinary Sciences \& Animal Husbandry, SKUAST-Jammu, INDIA \\ ${ }^{4}$ Division of Veterinary Parasitology, Faculty of Veterinary Sciences \& Animal Husbandry, SKUAST-Jammu, INDIA \\ "Corresponding author: AA Sheikh; E-mail: amirsheikh3468@gmail.com
}

Received: 05 Jan., 2021

Revised: 21 Jan., 2021

Accepted: 28 Jan., 2021

\begin{abstract}
Poultry production suffers huge losses due to heat stress, which is caused by high temperatures in many areas during the summer. Therefore, maximum production requires the elimination of the deleterious impacts of environmental stressors. The aim of this study was to check the amelioration of heat stress in commercial broilers by ascorbic acid supplementation on biochemical parameters viz., effect on plasma ascorbic acid, plasma albumin, plasma glucose, breast muscle $\mathrm{pH}$, thio-barbituric acid value. A total number of 96 birds were randomly divided into 8 groups, 4 groups of birds were kept at $\left(37 \pm 5.0^{\circ} \mathrm{C}\right)$ in heat stress conditions, while 4 other groups of birds were kept at $26 \pm 1.0^{\circ} \mathrm{C}$ (comfort temperature) using an air conditioner and each group consist of 12 birds. G1 was taken as control whereas G2, G3 and G4 were supplemented with $100 \mathrm{mg}, 200 \mathrm{mg}$ and $300 \mathrm{mg}$ of ascorbic acid respectively. G4 group supplemented with $300 \mathrm{mg}$ of ascorbic acid showed better results with overall plasma ascorbic acid values $(6.84 \pm 0.14)$ as compared to other supplemented and non-supplemented groups. However, G3 group supplemented with $200 \mathrm{mg}$ of ascorbic acid showed better results with overall plasma glucose (310.39 \pm 3.60$)$ and plasma albumin $(4.07 \pm 0.14)$ values. On $45^{\text {th }}$ day, G3 group supplemented with $200 \mathrm{mg}$ of ascorbic acid showed better results with respect to Breast muscle pH (6.2) and thiobarbituric acid (2.18) values. This shows Vitamin C/Ascorbic acid has potential antioxidant effect able to modulate physiological adjustments to mitigate the undesirable effects of exposure of broilers to high temperatures.
\end{abstract}

\section{HIGHLIGHTS}

( Supplementation with $300 \mathrm{mg}$ of ascorbic acid showed better results with overall plasma ascorbic acid values as compared to other supplemented and non-supplemented groups.

(0 Supplementation with $200 \mathrm{mg}$ of ascorbic acid showed better results with overall plasma glucose and plasma albumin values.

( O On $45^{\text {th }}$ day, supplementation with $200 \mathrm{mg}$ of ascorbic acid showed better results with respect to Breast muscle $\mathrm{pH}$ and thiobarbituric acid.

Keywords: Ascorbic acid, Biochemical parameters, Broilers, Heat Stress

During the current century, climate change, defined as the long-term imbalance of environmental factors such as temperature, radiation, wind and rainfall characteristics of a given region, is likely to be one of the main challenges facing mankind. The climate of the earth has warmed in the last century $\left(0.74 \pm 0.18^{\circ} \mathrm{C}\right)$ with the 1990 s and 2000 s being the warmest instrumental record. Changes in environmental

How to cite this article: Sheikh, A.A., Mishra, A., Nabi, B. and Sofi, O.M. (2021). Biochemical parameter derangement in commercial broilers during heat stress and their mitigation using ascorbic acid supplementation. J. Anim. Res., 11(1): 41-49.

Source of Support: None; Conflict of Interest: None 
variables, such as temperature, humidity and radiation, have been identified as possible threats to the growth and development of all domestic animal species, including poultry. The elevated ambient temperature accompanied by high humidity induced additional discomfort and increased the level of stress, resulting in physiological and metabolic activity depression. High ambient temperatures outside the range of the thermo-neutral zone in poultry have been recognised as one of the most fatal stressors among different environmental conditions, which adversely affect feed intake, growth rate, immunity and mortality (Niu et $a l ., 2009)$. Therefore, it is becoming increasingly important to avoid and alleviate heat stress (HS) toward summer high ambient temperatures. When chickens are exposed to high temperatures, to preserve body homeostasis, they try to reduce their body temperature within a limited range by self-thermal control. In particular, poultry exposure to summer HS is sufficiently stressful to induce their metabolic rate and physiological responses to deal with the thermal environment (Puthpongsiriporn et al., 2001). In fact, the processes of body homeostasis are involved in an endogenous cell defence mechanism that allows cells to deal with stressful HS that causes inflammation and oxidative stress (Molvarec et al., 2011).

If these environmental changes may not be reversed or changed by the animal or the cell, homeostasis may be disrupted and even death can occur. The withholding of feed, as well as the manipulation of the content of dietary protein, energy density and calcium, the use of carbonated water and the use of vitamins $\mathrm{C}$ and $\mathrm{E}$ are the approaches that are believed to reduce the effects of heat stress (Pardue and Taxton, 1986). The magnitude of the deleterious effects of heat stress is determined not only by its magnitude, but also by the status of cellular systems, particularly cellular antioxidant enzymes such as superoxide dismutase and glutathione peroxidase, as well as water or lipid soluble antioxidants such as ascorbic acid (AA) and $\alpha$-tocopherol (vitamin E) (Pigeolet et al., 1990). Thus, this experiment focused on the effect of ascorbic acid supplementation on certain plasma biochemical parameters in broiler chickens during cyclical heating episodes.

\section{MATERIALS AND METHODS}

The proposed research was carried out in the Department of Veterinary Physiology and Biochemistry, College of
Veterinary Science and Animal Husbandry, N.D.V.S.U., Jabalpur (M.P.), India. Jabalpur is located at latitude $23^{\circ} 10^{\prime} \mathrm{N}$ and longitude $79^{\circ} 56^{\prime} \mathrm{E}$ at an altitude of 411 meters in central India. It has a humid subtropical climate, typical of North-Central India.

\section{Birds and management}

A total of ninety-six (96) day-old chicks of commercial broiler birds were collected from private hatcheries. With prior approval from the Institutional Animal Ethics Committee, the birds were housed in the battery cage system in a well-ventilated room in the poultry experimental unit at the college. During the early era (brooding period) of growth artificial heat was given to chicks using thermostatically controlled electric brooders. By blow lamping, the battery brooders were cleaned, washed and disinfected and the complete house was fumigated four days before the start of the experiment using formaldehyde and potassium permanganate. With detergent, feeders and waterers were carefully washed. In each enclosure, aluminium plates of a reasonable size and small tin boxes were used to provide water during the early weeks. Due care was taken so that the chicks reach the feeder and waterer in the first week of age. In the first week of maturity, due care was taken so that the chicks hit the feeder and waterer. Later, feeders and waterers of large sizes were added to each cage in the opposite direction. During the experiment, the all-mash feeding system was introduced. Birds were made available all the time with new and safe drinking water. Thus, uniform, brooding, feeding, watering and housing conditions were provided for all the experimental groups throughout the entire period of research. Broiler birds were randomly divided into eight groups. Four groups of birds were kept at heat stress $\left(37 \pm 5.0^{\circ} \mathrm{C}\right)$ in heat stress conditions (May to June), while four other groups of birds were kept at $26 \pm 1.0^{\circ} \mathrm{C}$ (comfort temperature) using an air conditioner. During the experimental phase, broilers were held closed in a ventilated system for 45 days. The temperature and moisture of the experimental poultry unit was recorded using a digital thermo-hygrometer. Diets were developed in accordance with the requirements of the NRC (1994) provided in table 1 . 
Table 1: Formula and chemical composition of broiler ration

\begin{tabular}{lll}
\hline Ingredients & Starter \% & Finisher \% \\
\hline Maize & 58.805 & 59.50 \\
Soybean & 28 & 26 \\
Sunflower meal & 5 & 2.5 \\
Fish meal & 5 & 3 \\
Limestone & 1.0 & 0.8 \\
Di-calcium phosphate & 1.5 & 1.1 \\
Salt & 0.2 & 0.2 \\
DL- Methionine & 0.06 & 0.04 \\
Trace mineral Premix & 0.1 & 0.1 \\
Vitamin premix* & 0.15 & 0.15 \\
Vitamin B complex** & 0.015 & 0.015 \\
Choline chloride & 0.05 & 0.05 \\
Toxin binder & 0.05 & 0.05 \\
Protexim & 0.02 & - \\
Coccidiostat & 0.05 & 0.05 \\
De-oiled rise bran & - & 1.42 \\
Rape seed meal & - & 5 \\
Lysine & - & 0.02 \\
Total & 100 & 100 \\
\hline Nutrient Composition & & \\
\hline Crude protein (\%) & 21.66 & 18.98 \\
Metabolizable energy & 2843 & 2850 \\
(Kcal. ME/Kg)*** & 1.17 & 1.17 \\
Calcium (\%) & 0.496 & 0.5 \\
Available phosphorus (\%) & 1.24 & 1.22 \\
Lysine (\%) & &
\end{tabular}

*Trace mineral Premix: Mg-300, mn-55,I-0.4, fe-56, Zn-30 and $\mathrm{Cu}-4 \mathrm{~kg}-1$; ** Vitamin premix: Vitamin A-8250 IU, Vitamin $\mathrm{D}_{3}-$ 1200 IU, Vitamin K-1mg, Vitamin B1-2mg, Vitamin $\mathrm{B}_{2}-4 \mathrm{mg}$; Vitamin $B_{12}-10 \mathrm{mg}$, Percent of values specified by NRC, 1994, *** Calculated.

\section{Blood sampling}

Blood was obtained from individual birds on the stated day of the experiment for analysis of biochemical parameters, i.e. on the $15^{\text {th }}, 30^{\text {th }}$ and $45^{\text {th }}$ days. By cleaning the area by plucking the feather and wiping the area with an ethanol swab, the blood samples were collected. For blood collection, a 22 gauge needle was used. Both samples of blood were centrifuged for $30 \mathrm{~min}$ at $3000 \mathrm{rpm}$ and plasma was isolated. In the labelled storage vials of $2 \mathrm{ml}$ size, the plasma obtained was held and stored at $-20{ }^{\circ} \mathrm{C}$ until further examination.

\section{Biochemical analysis}

The plasma ascorbic acid was estimated using DCIP method described by (Omaye et al., 1979). Plasma glucose concentration was calculated by Trinder's method (Pileggi and Szuskeiweiz, 1974), using diagnostic kits obtained from Erba Diagnostics, Mannheim Gmbh, Germany. The blood glucose concentration was represented as $\mathrm{mg} /$ dl. The concentration of plasma albumin was calculated using diagnostic kits obtained from Erba Diagnostics, Mannheim GmbH, Germany, according to the method defined by Doumas et al. (1972). The plasma albumin concentration was expressed in $\mathrm{g} / \mathrm{dl}$ of albumin.

The $\mathrm{pH}$ was calculated using the iodoacetate method modification stated by Petracci et al. (2004). Approximately $2.5 \mathrm{~g}$ of breast meat was removed from the cranial end of each fillet, minced with a mincer, homogenised for 30 seconds in $25 \mathrm{~mL}$ of $5 \mathrm{mM}$ iodoacetate solution containing $150 \mathrm{mM}$ potassium chloride and a $\mathrm{pH}$ metre was used to assess the $\mathrm{pH}$ of the homogenate. Lipid peroxidation for TBA-reactive substances was calculated by a micro-method (TBARS). Approximately $100 \mathrm{mg}$ of liver was incubated in $0.5 \mathrm{~mL}$ of $50 \%$ trichloroacetic acid containing $1.3 \%$ (wt/ vol) thiobarbituric acid (dissolved at $60{ }^{\circ} \mathrm{C}$ ) and heated for $1 \mathrm{~h}$ at $60{ }^{\circ} \mathrm{C}$, accompanied by a supernatant absorption determination at $532 \mathrm{~nm}$. Tetraethoxypropane, which spontaneously decomposes to form malondialdehyde (MDA) in an aqueous setting, was used as a norm and MDA equivalents were expressed as absorbance. MDA equivalents were determined after blank (water) subtraction, turbidity correction estimated at $650 \mathrm{~nm}$ and TBA reagent dilution from the water present in the meat.

\section{Statistical analysis}

The reported data was analysed statistically using Completely Randomized Design (Snedecor and Cochran, 1994). Using the Duncan Multiple Range test, various conditions and treatment groups were compared (DMRT).

\section{RESULTS AND DISCUSSION}

The data recorded and analysed for plasma ascorbic acid are shown in Table 2. The overall mean concentration of AA showed non-significant difference between comfort and heat stressed birds in ascorbic acid supplemented 
Table 2: Mean plasma ascorbic acid concentration $(\mathrm{mg} / \mathrm{dl})$ of broilers at different intervals

\begin{tabular}{llllll}
\hline Period & Condition & G1 & G2 & G3 & G4 \\
\hline \multirow{2}{*}{$15^{\text {th }}$ day } & Comfort & $4.89^{\mathrm{B}} \pm 0.29(12)$ & $5.63^{\mathrm{B}} \pm 0.17(12)$ & $6.85^{\mathrm{A}} \pm 0.21(12)$ & $7.29^{\mathrm{A}} \pm 0.21(12)$ \\
& Heat & $5.35^{\mathrm{B}} \pm 0.21(12)$ & $6.08^{\mathrm{AB}} \pm 0.22(12)$ & $6.56^{\mathrm{A}} \pm 0.28(12)$ & $7.20^{\mathrm{A}} \pm 0.20(12)$ \\
\multirow{2}{*}{$30^{\text {th }}$ day } & Comfort & $4.09^{\mathrm{B}} \pm 0.19(12)$ & $6.57^{\mathrm{A}} \pm 0.31(12)$ & $6.58^{\mathrm{A}} \pm 0.31(12)$ & $7.33^{\mathrm{A}} \pm 0.29(12)$ \\
& Heat & $5.87 \pm 0.26(12)$ & $6.77 \pm 0.21(12)$ & $6.47 \pm 0.19(12)$ & $6.27 \pm 0.16(12)$ \\
\multirow{2}{*}{$45^{\text {st }}$ day } & Comfort & $4.09^{\mathrm{B}} \pm 0.20(12)$ & $6.77^{\mathrm{A}} \pm 0.30(12)$ & $6.71^{\mathrm{A}} \pm 0.16(12)$ & $6.95^{\mathrm{A}} \pm 0.23(12)$ \\
& Heat & $5.19^{\mathrm{B}} \pm 0.23(12)$ & $6.27^{\mathrm{AB}} \pm 0.26(12)$ & $7.43^{\mathrm{A}} \pm 0.25(12)$ & $7.06^{\mathrm{A}} \pm 0.27(12)$ \\
\hline \multirow{2}{*}{ Overall mean } & Comfort & $4.36^{\mathrm{C}} \pm 0.15(36)$ & $6.32^{\mathrm{B}} \pm 0.17(36)$ & $6.71^{\mathrm{AB}} \pm 0.14(36)$ & $7.19^{\mathrm{A}} \pm 0.14(36)$ \\
\cline { 2 - 6 } & Heat & $5.47^{\mathrm{b}} \pm 0.14(36)$ & $6.37^{\mathrm{ab}} \pm 0.14(36)$ & $6.82^{\mathrm{a}} \pm 0.16(36)$ & $6.84^{\mathrm{a}} \pm 0.14(36)$ \\
\hline
\end{tabular}

Means bearing different superscripts within same row differ significantly $\left({ }^{A B C} ; \mathrm{p}<0.01\right.$, ab; $\mathrm{p}<0.05$ ); Means bearing different superscripts within same column differ significantly ( ${ }^{\mathrm{PQ}}$; $\mathrm{p}<0.01$, ${ }^{\mathrm{pq}}$; $\left.\mathrm{p}<0.05\right)$; Comfort $\left(26 \pm 1^{\circ} \mathrm{C}\right)$, Heat $\left(37 \pm 5^{\circ} \mathrm{C}\right)$, G1 (Control), G2 (100 mg AA), G3 (200 mg AA), G4 (300 mg AA).

groups. Maximum $(7.19 \pm 0.14 \mathrm{mg} / \mathrm{dl})$ and minimum $(4.36 \pm 0.15 \mathrm{mg} / \mathrm{dl})$ AA concentrations were found in the G4 and control groups, respectively, which vary significantly $(\mathrm{p}<0.01)$. However, a non-significant difference was observed in G4 and G3 and a similar trend was observed between G3 and G2. Maximum $(6.84 \pm 0.14 \mathrm{mg} / \mathrm{dl})$ and minimum $(5.47 \pm 0.14 \mathrm{mg} / \mathrm{dl})$ AA concentrations were observed in the G4 and control groups, respectively, which differ significantly $(p<0.05)$. In addition, a non-significant difference was observed in G2, G3 and G4, while a similar trend was observed in observed between G1 and G2.

In addition to the varying concentration of AA, the overall mean concentration of plasma AA showed a non-significant difference between comfort and heat-stressed broilers in all groups. Mahmoud et al. (2004) reported that dietary AA supplementation increased plasma AA and maintained it at high levels after heating but in non-ascorbic acid (NAA) broiler birds, only heat elevated plasma AA, although the increase was non-significant, which corresponds to the present findings. AA supplementation resulted in a significant increase in plasma AA (18.8 to $26.6 \mu \mathrm{g}$ / $\mathrm{ml}$ ) compared to the N-AA group ( 8.7 to $16.4 \pm 0.93 \mu \mathrm{g}$ / $\mathrm{ml}$ ) which is not consistent with our findings. As per our reports, maximum $(7.19 \mathrm{mg} / \mathrm{dl})$ and minimum $(4.36 \mathrm{mg} /$ dl) AA concentrations were observed in the $300 \mathrm{mg}$ AA complemented group and control group, respectively, which differ significantly. In the present research, plasma AA content has been shown to be significantly higher in birds fed AA supplemented diets compared to nonsupplemented ones. Similar findings were also reported by Lohakare et al. (2005).
With the levels supplied and their plasma levels during the investigation, an important linear positive trend in AA was observed. AA is actively transported into tissues and its use increases during stress periods such as heat and the synthesising ability of the bird can become inefficient, thus reducing plasma AA concentrations, which may be the case in the current investigation in the non-supplemented groups. Under stressful conditions, the effectiveness of supplementing AA in birds depends on its ability to increase plasma AA concentrations, thus avoiding tissue depletion. By decreasing heat output, the AA either decreases heat load or increases heat loss by affecting thermal exchange avenues between the body and the environment.

\section{Plasma glucose}

The data recorded and analysed for plasma glucose are shown in Table 3. In the groups supplemented with ascorbic acid, the average mean glucose concentration showed no significant difference between comfort and heat stressed birds. The G3 and G4 groups differ significantly $(p<0.01)$ from $G 1$ in comfort conditions, but no significant difference between the G2, G3 and G4 groups was observed. The G1 and G2 classes were also not significantly different. No significant difference between G3 and G4 was observed in heat-stressed conditions. Both in G2 and G4, a similar pattern was also observed. The control group G1 varies significantly $(p<0.01)$ from all heat stressed groups treated with ascorbic acid, showing minimum glucose concentrations $(216.19 \pm 6.79 \mathrm{mg} / \mathrm{dl})$. 
Table 3: Mean plasma glucose concentration $(\mathrm{mg} / \mathrm{dl})$ of broilers at different intervals

\begin{tabular}{llllll}
\hline Period & Condition & G1 & G2 & G3 & G4 \\
\hline \multirow{2}{*}{$15^{\text {th }}$ day } & Comfort & $266.5^{\mathrm{B}} \pm 11.6(12)$ & $283.9^{\mathrm{AB}} \pm 17.4(12)$ & $313.75^{\mathrm{A}} \pm 6.73(12)$ & $304.92^{\mathrm{AB}} \pm 7.71(12)$ \\
& Heat & $243.1^{\mathrm{B}} \pm 10.8(12)$ & $273.01^{\mathrm{AB}} \pm 8.84(12)$ & $313.00^{\mathrm{A}} \pm 7.84(12)$ & $291.00^{\mathrm{A}} \pm 18.5(12)$ \\
\multirow{2}{*}{$30^{\text {th }}$ day } & Comfort & $252.51^{\mathrm{B}} \pm 7.78(12)$ & $292.2^{\mathrm{AB}} \pm 15.0(12)$ & $311.54^{\mathrm{A}} \pm 6.16(12)$ & $290.2^{\mathrm{AB}} \pm 16.1(12)$ \\
& Heat & $223.50^{\mathrm{C}} \pm 7.74(12)$ & $271.00^{\mathrm{B}} \pm 10.2(12)$ & $313.67^{\mathrm{A}} \pm 7.08(12)$ & $293.63^{\mathrm{AB}} \pm 9.75(12)$ \\
\multirow{2}{*}{$45^{\text {st }}$ day } & Comfort & $238.83^{\mathrm{B}} \pm 7.55(12)$ & $269.8^{\mathrm{B}} \pm 13.8(12)$ & $310.00^{\mathrm{A}} \pm 9.85(12)$ & $307.50^{\mathrm{A}} \pm 3.13(12)$ \\
& Heat & $182.02^{\mathrm{B}} \pm 9.33(12)$ & $276.2^{\mathrm{A}} \pm 10.3(12)$ & $304.5^{\mathrm{A}} \pm 2.78(12)$ & $289.50^{\mathrm{AB}} \pm 6.77(12)$ \\
\hline \multirow{2}{*}{ Overall mean } & Comfort & $252.61^{\mathrm{B}} \pm 5.48(36)$ & $281.94^{\mathrm{AB}} \pm 8.80(36)$ & $311.94^{\mathrm{A}} \pm 4.35(36)$ & $300.86^{\mathrm{A}} \pm 6.01(36)$ \\
\cline { 2 - 6 } & Heat & $216.19^{\mathrm{C}} \pm 6.79(36)$ & $273.40^{\mathrm{B}} \pm 5.50(36)$ & $310.39^{\mathrm{A}} \pm 3.60(36)$ & $291.38^{\mathrm{AB}} \pm 7.11(36)$ \\
\hline
\end{tabular}

Means bearing different superscripts within same row differ significantly $\left({ }^{\mathrm{ABC}} ; \mathrm{p}<0.01\right)$; Comfort $\left(26 \pm 1^{\circ} \mathrm{C}\right)$, Heat $\left(37 \pm 5^{\circ} \mathrm{C}\right)$; $\mathrm{G} 1(\mathrm{Control})$, G2 (100 mg AA), G3 (200 mg AA), G4 (300 mg AA).

Supplementation of $100 \mathrm{mg}, 200 \mathrm{mg}$ and $300 \mathrm{mg} \mathrm{AA}$ in feed, it was found that the overall mean glucose concentration showed a non-significant difference between comfort and heat-stressed birds in all groups. Similar to the present investigation, several workers reported blood glucose levels in broilers under different thermal stress conditions (Aksit et al., 2006; Olanrewaju et al., 2010). In this study, significantly higher levels of plasma glucose were observed in $200 \mathrm{mg}$ AA complemented birds compared to heat-stressed chickens. In comfort, the present plasma glucose levels on the 45th day with AA supplementation $(310.00 \pm 9.85 \mathrm{mg} / \mathrm{dl})$ were comparable (Borges et al., 2004) at $41^{\circ} \mathrm{C}$ at 6 weeks of age Cobb broiler $(283.4 \mathrm{mg} / \mathrm{dl})$. Higher glucose levels have been reported by supplementation of AA during heat stress condition (Aksit et al., 2006; Olanrewaju et al., 2010). Sujatha et al. (2010) reported that the concentration of glucose in synthetic (100 g/tone of fed) AA supplemented birds was significantly lower compared to the control group at 3 rd and 5 th week in broiler birds that is not similar to the findings. Khatibjoo et al., (2014) reported that stress significantly changed glucose concentrations in broilers; however, it did not differ significantly, which is in disagreement with the findings.

The increase in glucose levels at higher ambient temperatures would be due to the endocrine stress regulation mechanism. Hypoglycemia caused by stress conditions led to the stimulation of the hypothalamus and the release of ACTH from the anterior pituitary gland, which resulted in increased secretions of the adrenal cortical steroid. Continuous stimulation of the adrenal cortex led to chronically high levels of corticosteroids. These hormones are responsible for the formation of glucose from the body's carbohydrate, lipid and protein reserves. Among the 42 adaptive responses to $\mathrm{ACTH}$, one of the responses reported was an increase in blood glucose levels (Borges et al., 2004). Glucocorticoids also have primary effects on metabolism, stimulating glucogenesis leading to increased blood glucose levels (Khatibjoo et al., 2014). These results could be explained by that, birds under environmental stress underwent an increase in plasma glucose which may be correlated with increase in corticosterone hormone secretion to supply the body with energy (Siegel, 1995).

\section{Plasma albumin}

The data recorded and analysed for plasma albumin concentrations are shown in Table 4. The overall mean concentration of albumin showed a non-significant difference between comfort and heat-stressed birds in groups supplemented by ascorbic acid. In comfort conditions, the G3 and G4 groups differ significantly $(p<0.01)$ from the $G 1$, but there was a significant difference between the G2, G3 and G4 groups. Also, G1 and G2 are not significantly different. A significant difference $(p<0.01)$ between the groups G1, G3 and G4 was observed in the heat-stressed condition. A similar trend has also been observed between G2 and G3. However, a nonsignificant difference between G1 and G2 was observed. A similar trend has also been observed between the G2 and G4 groups. 
Table 4: Mean plasma albumin concentration $(\mathrm{g} / \mathrm{dl})$ of broilers at different intervals

\begin{tabular}{llllll}
\hline Period & Condition & G1 & G2 & G3 & G4 \\
\hline \multirow{2}{*}{$15^{\text {th }}$ day } & Comfort & $1.65^{\mathrm{B}} \pm 0.08(12)$ & $2.42^{\mathrm{AB}} \pm 0.08(12)$ & $3.52^{\mathrm{A}} \pm 0.13(12)$ & $3.18^{\mathrm{A}} \pm 0.10(12)$ \\
& Heat & $1.33^{\mathrm{b}} \pm 0.87(12)$ & $1.91^{\mathrm{ab}} \pm 0.10(12)$ & $3.48^{\mathrm{a}} \pm 1.84(12)$ & $3.19^{\mathrm{ab}} \pm 0.15(12)$ \\
\multirow{2}{*}{$30^{\text {th }}$ day } & Comfort & $1.76^{\mathrm{b}} \pm 0.14(12)$ & $2.91^{\mathrm{ab}} \pm 0.15(12)$ & $4.21^{\mathrm{a}} \pm 0.21(12)$ & $3.84^{\mathrm{a}} \pm 0.19(12)$ \\
& Heat & $1.60^{\mathrm{B}} \pm 0.06(12)$ & $2.58^{\mathrm{AB}} \pm 0.12(12)$ & $4.00^{\mathrm{A}} \pm 0.22(12)$ & $3.51^{\mathrm{B}} \pm 0.13(12)$ \\
\multirow{2}{*}{$45^{\text {st }}$ day } & Comfort & $1.83^{\mathrm{b}} \pm 0.12(12)$ & $3.56^{\mathrm{ab}} \pm 0.16(12)$ & $4.94^{\mathrm{a}} \pm 0.19(12)$ & $4.47^{\mathrm{ab}} \pm 0.14(12)$ \\
& Heat & $1.60^{\mathrm{C}} \pm 0.09(12)$ & $2.67^{\mathrm{BC}} \pm 0.12(12)$ & $4.72^{\mathrm{A}} \pm 0.18(12)$ & $3.80^{\mathrm{AB}} \pm 0.18(12)$ \\
\hline \multirow{2}{*}{ Overall mean } & Comfort & $1.74^{\mathrm{B}} \pm 0.07(36)$ & $2.96^{\mathrm{AB}} \pm 0.11(36)$ & $4.22^{\mathrm{A}} \pm 0.14(36)$ & $3.83^{\mathrm{A}} \pm 0.12(36)$ \\
\cline { 2 - 6 } & Heat & $1.51^{\mathrm{C}} \pm 0.05(36)$ & $2.39^{\mathrm{BC}} \pm 0.09(36)$ & $4.07^{\mathrm{A}} \pm 0.14(36)$ & $3.50^{\mathrm{B}} \pm 0.10(36)$ \\
\hline
\end{tabular}

Means bearing different superscripts within same row differ significantly $\left({ }^{\mathrm{ABC}} ; \mathrm{p}<0.01\right.$, ${ }^{\text {abc}}$; $\left.\mathrm{p}<0.05\right)$; Comfort $\left(26 \pm 1^{\circ} \mathrm{C}\right), \mathrm{Heat}\left(37 \pm 5^{\circ} \mathrm{C}\right)$; $\mathrm{G} 1$ (Control), G2 (100 mg AA), G3 (200 mg AA), G4 (300 mg AA).

The overall mean concentration of albumin showed nonsignificant difference between comfort and heat stressed birds in all the groups supplemented with AA. In both heatstressed and comfort conditions, a significant difference was observed in the 200 and $300 \mathrm{mg}$ AA supplemented broilers compared to the control group. In the present findings, the AA supplemented birds had higher serum albumin levels compared to the control group of broilers. Sabah et al. (2008) reported that the $750 \mathrm{mg} / \mathrm{Kg}$ AA dose provided the highest serum albumin value followed by $500,250 \mathrm{mg} / \mathrm{Kg}$ AA supplementation, which is at odds with our findings that $200 \mathrm{mg}$ AA resulted in the highest albumin concentration followed by $300 \mathrm{mg}$ and $100 \mathrm{mg}$ complemented.

Results from the present investigation also indicate that dietary AA has beneficial effects on commercial broilers. Kutlu and Forbes (1993) reported that vitamin C supplementation increases the concentrations of serum albumin. The present study also recorded elevated concentrations of serum albumin in birds that received vitamin $\mathrm{C}$. The probable reason for such an increase in albumin concentrations may be due to the fact that corticosteroid secretion increases as a response to stress at temperatures above the thermoneutral zone. Mckee et al. (1997) reported that ascorbic acid supplementation reduces the synthesis of corticoid hormones in birds under heat stress. As corticosteroids induce gluconeogenesis from non-carbohydrate precursors such as lactate, amino acids and glycerol (Linne and Ringsrud, 1999), a reduction in glucocorticoid secretion could reduce lipid and protein catabolism (Kucuk et al., 2003). The increase in serum albumin concentrations observed in the experimental groups of the present investigation could be partly explained by the fact that this increase could be due to the reduction of the synthesis (lipids and proteins through non-carbohydrate sources) and the secretion of corticosteroids in birds supplemented by vitamin $\mathrm{C}$.

\section{Breast muscle $\mathrm{pH}$ and thiobarbituric acid value}

The data recorded for breast muscle $\mathrm{pH}$ and thiobarbituric acid value is shown in Table 5. On day 45, in comfort conditions, a higher breast muscle $\mathrm{pH}$ of 6.8 and 6.7 was observed in the control and G1 sacrificed broilers, while a lower pH of 6.4 was observed in G3, supplemented by $200 \mathrm{mg}$ AA. On day 45, in a heat-stressed condition, a higher breast muscle $\mathrm{pH}$ of 6.6 was observed in the control sacrificed broiler group, while a lower $\mathrm{pH}$ of 6.2 was recorded in G3, supplemented by $200 \mathrm{mg}$ AA.

On day 45, in both comfort and heat-stressed condition, supplementation with $200 \mathrm{mg}$ AA recorded a numerically lower $\mathrm{pH}$ of the breast muscle compared to control broilers. The $\mathrm{pH}$ of the sacrificed birds is comparatively higher than the final $\mathrm{pH}$ obtained after a few hours of sacrifice, which indicates the beneficial effect of AA supplementation in broilers. Present findings are in disagreement with the findings of Kadim et al. (2009), who reported that ascorbic acid supplementation in drinking water affects the quality of the meat and that the Pectoralis muscles collected during the hot season had significantly higher $\mathrm{pH}$ levels than those collected during the cool season. They also reported that chickens reared in an open house had a significantly higher $\mathrm{pH}(\mathrm{p}<0.05)$ than those reared in a closed house. The likely reason for such reports may 
Table 5: Breast muscle $\mathrm{pH}$ and thiobarbituric acid value in liver homogenates of broilers

\begin{tabular}{llllll}
\hline Parameter & Condition & G1 & G2 & G3 & G4 \\
\hline \multirow{2}{*}{ Breast Muscle pH } & Comfort & 6.8 & 6.7 & 6.4 & 6.6 \\
& Heat & 6.6 & 6.5 & 6.2 & 6.5 \\
\multirow{2}{*}{ TBA (nmol MDA equivalent/mg wet tissue) } & Comfort & 5.01 & 2.91 & 2.82 & 3.51 \\
& Heat & 5.74 & 3.58 & 2.18 & 2.64 \\
\hline
\end{tabular}

Comfort $\left(26 \pm 1^{\circ} \mathrm{C}\right)$, Heat $\left(37 \pm 5^{\circ} \mathrm{C}\right)$; G1 (Control), G2 (100 mg AA), G3 (200 mg AA), G4 (300 mg AA).

be that rearing broiler chickens for 5-6 weeks may not be long enough for ascorbic acid to have an effect on muscle metabolism, which may also be the reason for the findings.

The possible justification for the present findings may be that high ambient temperatures reduce bird feed intake and impose physiological stresses that activate glycogenolysis in the skeletal muscle. Physiologically stressed birds use glucose and gluconeogenic precursors as their main oxidative fuel. Low muscle glycogen content due to fatigue or chronic stress before death results in high $\mathrm{pH}$ values and minimal rigour reduction, which could be one of the major factors leading to deterioration in the quality of the meat. Ogunwole et al. (2013) reported that the $\mathrm{pH}$ of broiler meat was not statistically different $(\mathrm{p}>0.05)$. The carcass and meat $\mathrm{pH}$ of birds in all dietary AA treatments had a higher final $\mathrm{pH}$, which decreased gradually over time, which is consistent with the findings. This could be the result of declining metabolic glycolysis in the meat, as oxidative respiration with post-mortem passing time ceases. Swatland (2008) reported implicit interactions between temperature and $\mathrm{pH}$ because glycolysis is exothermic and $\mathrm{pH}$ effects are very severe when the muscle is still near body temperature.

In comfort, the higher TBA value of sacrificed broilers on day 45 was $5.01 \mathrm{nmol}$ MDA equivalent $/ \mathrm{mg}$ of wet tissue in the control group, while the lower TBA value was $2.82 \mathrm{nmol} \mathrm{MDA}$ equivalent/mg of wet tissue in G3, supplemented by $200 \mathrm{mg}$ AA. In heat-stressed condition, the higher TBA value of sacrificed broilers on day 45 was $5.74 \mathrm{nmol}$ MDA equivalent/mg of wet tissue in the control group, while the lower TBA value was $2.18 \mathrm{nmol}$ MDA equivalent/mg of wet tissue in G3, supplemented by $200 \mathrm{mg}$ AA. The thiobarbituric acid value (nmol MDA equivalent/mg wet tissue) of sacrificed broilers was numerically lower in $200 \mathrm{mg}$ AA supplemented birds compared to control birds during comfort and heat stress conditions. Results from the present investigation show that $200 \mathrm{mg}$ AA and $300 \mathrm{mg}$ AA supplementation in broilers have been shown to be beneficial in reducing lipid peroxidation in chickens. Young et al. (2003) reported that chickens fed a diet complemented by ascorbic acid $(1,000 \mathrm{ppm})$ decreased TBA values in non-stressed birds in the major muscles of Pectoralis, which is agreed to be reported. Increased antioxidative status thus seemed to protect against stress-induced increase in lipid oxidation in ascorbic acid- supplemented chickens.

Jang et al. (2014) reported that dietary supplementation with vitamin $\mathrm{C}$ undergoing summer $\mathrm{HS}$ in broilers significantly decreased (TBA value) lipid peroxidation in the liver compared to the control group is consistent with our findings. Dietary vitamin C significantly decreased hepatic lipid peroxidation in this study. In particular, several studies have shown that dietary vitamin $\mathrm{C}$ has shown a significant decrease in the MDA value as an indicator of lipid peroxidation (Cherian et al., 1996; Sahin et al., 2002). Dietary vitamins may therefore have a positive effect in preventing lipid peroxidation in birds exposed to summer HS, indicating that there is a strong functional association between pro-inflammatory cytokines and the antioxidant system in birds.

\section{CONCLUSION}

With dietary supplementation of ascorbic acid, a linear positive trend in plasma ascorbic acid, plasmaglucose and plasma albumin was observed this could be due to the reduction of the synthesis from non-carbohydrate sources and the secretion of corticosteroids in birds supplemented by vitamin $\mathrm{C}$ (ascorbic acid). Also reduction in breast muscle $\mathrm{pH}$ and thiobarbituric acid value indicates amelioration in oxidative stress via reduced lipid peroxidation in chickens by supplementation of ascorbic acid. 


\section{ACKNOWLEDGEMENTS}

The authors would like to acknowledge, M.P. Biotechnology Council, Bhopal (M.P) for providing financial assistance for the research project.

\section{REFERENCES}

Aksit, M., Yalcin, S., Ozkan, S., Metin, K. and Ozdemir, D. 2006. Effect of temperature during rearing and crating on stress parameters and meat quality of broilers. Poult. Sci., 85: 1867- 1874.

Borges, S.A., Fischer, D.S., Majorka, A., Hooge, D.M. and Cummings, K.R. 2004. Physiological responses of broiler chickens to heat stress and dietary electrolyte balance. Poult. Sci., 83: 1551-1558.

Cherian, G., Wolfe, F.W. and Sim, J.S. 1996. Dietary oils with added tocopherol: Effects on egg or tissue tocopherols, fatty acids, and oxidative stability. Poul. Sci., 75: 423-431.

Doumas, B.T., Arends, R.L. and Pinto, P.C. 1972. Standard Methods of Clinical Chemistry, $7^{\text {th }}$ Edn., Academic Press, Chicago, pp $175-189$.

Jang, I.S., Ko, Y.H., Moon, Y.S. and Sohn, S.H. 2014. Effects of vitamin $\mathrm{C}$ or $\mathrm{E}$ on the pro-inflammatory cytokines, heat shock protein 70 and antioxidant status in broiler chicks under summer conditions. Asian-Australas. J. Anim. Sci., 5: 749-756.

Kadim, I.T., Al-Qamshui, B.H.A., Mahgoub, O., Al-Marzooqi, W. and Johnson, E.H. 2009. The effects of ascorbic acid and seasonal temperatures on meat quality characteristics of broiler chickens maintained in open-sided and closed houses. Int. J. Poult. Sci., 8: 733-739.

Khatibjoo, A., Ranjbar, K., Neamati, M. and Fattahnia, F. 2014. Effects of vitamin C, Echium amoenum and lavender extract on blood metabolite and meat quality of broiler chickens under transport stress. G.J. Anim. Scientific Res., 2: 159-169.

Kucuk, O., Sahin, N. and Sahin, K. 2003. Supplemental zinc and vitamin A can alleviate negative effects of heat stress in broiler chickens. Biol. Trace Elem. Res., 94: 225-235.

Kutlu, H.R. and Forbes, J.M. 1993. Changes in growth and blood parameters in heat stressed broiler chicks in response to dietary ascorbic acid. Livest. Prod. Sci., 36: 335-350.

Linne, J.J. and Ringsrud K.M., 1999. Chemistry in Clinical Laboratory Science. $4^{\text {th }}$ Edn., Mosby Academic Publisher Inc., USA, pp. 264-266.

Lohakare, J.D., Chae, B.J. and Hahn, T.W. 2005. Effects of feeding methods (water vs. feed) of vitamin $\mathrm{C}$ on growth performance and carcass characteristics in broiler chickens. Asian-Australas. J. Anim. Sci., 17: 1112-1117.
Mahmoud, K.Z., Edens, F.W., Eisen, E.J. and Havenstein, G.B. 2004. Ascorbic acid decreases heat shock protein 70 and plasma corticosterone response in broilers (Gallus gallus domesticus) subjected to cyclic heat stress. Comp. Biochem. Physiol. B., 137: 35-42.

Mckee, J.S., Harrison, P.C. and Riskowski, G.L. 1997. Effect of supplemental ascorbic acid on the energy conversion of broiler chicks during heat stress and feed withdrawal. Poult. Sci., 76: 1278-1286.

Molvarec, A., Szarka, A., Walentin, S., Beko, G., Karádi, I., Prohászka, Z. and Rigó Jr, T. 2011. Serum heat shock protein 70 levels in relation to circulating cytokines, chemokines, adhesion molecules and angiogenic factors in women with preeclampsia. Clinica. Chimica. Acta., 412:1957-1962. .

Niu, Z.Y., Liu, F.Z., Yan, Q.L. and Li, W.C. 2009. Effect of different levels of vitamin $\mathrm{E}$ on growth performance and immune responses of broiler under heat stress. Poult. Sci., 88: 2101-2107.

NRC. 1994. Nutrient Requirement of Poultry $9^{\text {th }}$ Rev Edn., National Research Council, National Academy Press, Washington, DC, 20418.

Ogunwole, O.A., Oso, Y.A.A., Omotoso, R.R., Majekodunmi, B.C., Ayinde, B.O. and Oikeh, I. 2013. Performance, carcass characteristics and meat physico-chemical properties of broiler chickens fed graded levels of supplemental ascorbic acid. Agri. Biolo. J. N. America, 4(4): 485-495.

Olanrewaju, H.A., Purswell, J.L. and Collier, S.D. 2010. Effect of ambient temperature and light intensuity on physiological reactions of broiler chickens. Poult. Sci., 89: 2668- 2677.

Omaye, S.T., Turnbull, J.D. and Sauberlich, H.E. 1979. Selected methods for the determination of ascorbic acid in animal cells, tissues and fluids. Method Enzymol., 62: 1-7.

Pardue, S.L. and Thaxton, J.P. 1986. Ascorbic acid in poultry: a review. World Poultry Sci. J., 42: 107-123.

Petracci, M., Betti, M. and Cavani, C. 2004. Color variation and characterization of broiler breast meat during processing in Italy. Poult. Sci., 83: 2085-2092

Pigeolet, E., Carbisier, P., Houbion, A., Lambert, D., Machiels, C. and Raes, M. 1990. Glutathione peroxidase, superoxide dismutase and catalase inactivation by peroxides and oxygen derived free radicals. Mech. Ageing Dev., 51: 283-297.

Pileggi, V.J. and Szuskeiweiz. 1974. Carbohydrates. In: Henry Richard J., C. Canon Donald and W. Winkelman James (eds.) Clinical Chemistry. Principles and Techniques. $2^{\text {nd }}$ Edn., Harper and Row Publishers, New York, pp. 1265-1325.

Puthpongsiriporn, U., Scheideler, S.E., Sell, J.L. and Beck, M.M. 2001. Effects of vitamin $\mathrm{E}$ and $\mathrm{C}$ supplementation on performance, in vitro lymphocyte proliferation, and 
antioxidant status of laying hens during heat stress. Poult. Sci., 80: 1190-1200.

Sabah, E.M.K., Mohammed, A.M.M. and Abdel, G.S.M. 2008. Effect of feed restriction and ascorbic acid supplementation on performance of broiler chicks reared under heat stress. Res. J. Anim. Vet. Sci., 3: 1-8.

Sahin, K., Kucuk, O., Sahin, N. and Sari, M. 2002. Effects of vitamin $\mathrm{C}$ and vitamin $\mathrm{E}$ on lipid peroxidation status, some serum hormone, metabolite, and mineral concentrations of Japanese quails reared under heat stress $\left(34^{\circ} \mathrm{C}\right)$. Int. J. Vitam. Nutr. Res., 72: 91-100.
Siegel, H.S. 1995. Stress, strains and resistance. B. Poul. Sci., 36: $03-22$

Sujatha, V., Korde, J.P., Rastogi, S.K, Maini, S, Ravikanth, K. and Rekhe, D.S. 2010. Amelioration of heat stress induced disturbances of the antioxidant defense system in broilers. $J$. Vet. Med. Anim. Health, 2: 18-28.

Swatland, H.J. 2008. How pH causes paleness or darkness in chicken breast meat. Meat Sci., 80: 396-400.

Young, J.C., Barral, J.M. and Hartl, F.U. 2003. More than folding: localized functions of cytosolic chaperones. Trends Biochem. Sci., 28: 541-547. 
